\title{
Produção de mudas de tangerineira 'Ponkan' em sistema hidropônico'
}

\author{
Production of Ponkan tangerine seedlings in a hydroponic system
}

\author{
Aline das Graças Souza2*, Valdemar Faquin ${ }^{3}$, Nilton Nagib Chalfun ${ }^{4}$ e Ademária Aparecida Souza ${ }^{5}$
}

\begin{abstract}
RESUMO - A produção de mudas enxertadas em hidroponia vem sendo utilizada com sucesso para várias culturas, devido à precocidade de sua obtenção e à isenção de patógenos, principalmente de solos e substratos. Assim, realizou-se essa pesquisa com o objetivo de estudar em sistema hidropônico, a viabilidade da produção de porta-enxertos de limoeiro 'Cravo' através da determinação do diâmetro ótimo dos porta-enxertos para execução de enxertia da cultivar tangerineira 'Ponkan' e avaliação da produção de mudas enxertadas. O experimento foi conduzido em casa de vegetação, no Setor de Hidroponia do Departamento Ciência do Solo na Universidade Federal de Lavras, Lavras, MG, em duas etapas. Na primeira etapa pesquisou-se, o crescimento dos porta-enxertos de limoeiro 'Cravo' (Citrus limonia Osbeck). Na segunda etapa, avaliou-se, o diâmetro ótimo dos portaenxertos para execução da enxertia e a viabilidade da produção de mudas enxertadas da cultivar tangerineira 'Ponkan', (Citrus reticulata Blanco) em porta-enxertos de limoeiro 'Cravo'. Ambas as etapas foram conduzidas em sistema hidropônico utilizando o delineamento experimental inteiramente casualizado. Os tratamentos de cada experimento foram épocas de avaliação (semanas) composta por cinco repetições de cinco plântulas, totalizando 25 porta-enxertos por tubete. Os porta-enxertos de Limoeiro 'Cravo' com diâmetro de $7 \mathrm{~mm}$, foi o mais apropriado à propagação de mudas da cultivar tangerineira 'Ponkan', (Citrus reticulata Blanco), apresentando o melhor crescimento vegetativo do enxerto, sobressaindo com tempo 91 DAE, superando o tempo para a formação das mudas cítricas obtidas com os demais diâmetros (4 mm; $5 \mathrm{~mm}$ e $6 \mathrm{~mm}$ ). O sistema hidropônico mostrou ser uma técnica viável para a propagação de mudas cítricas.
\end{abstract}

Palavras-chave: Tangerina. Hidroponia. Plantas-propagação.

\begin{abstract}
The production in hydroponics of grafted seedlings has been used successfully for various crops, due to its precocity and absence of pathogens, mainly from the soil and substrates. This research was therefore carried out with the aim of studying the feasibility of the production of Rangpur-lime rootstock in a hydroponic system, by determining the optimal diameter of the rootstock for grafting onto the tangerine cultivar Ponkan, and by evaluating the production of the grafted seedlings. The experiment was conducted in two stages in a greenhouse in the Hydroponics Sector of the Department of Soil Science at the Federal University of Lavras in Minas Gerais. In the first stage, the growth of Rangpur lime rootstock (Citrus limonia Osbeck) was investigated. In the second stage, the optimal diameter of the rootstock for grafting was evaluated together with the viability of the production of seedlings of the tangerine cultivar Ponkan (Citrus reticulata Blanco) when grafted onto rootstock of the Rangpur lime. Both steps were carried out in a hydroponic system, using a completely randomized experimental design. The treatments of each experiment were times of evaluation (in weeks) consisting of five replications of five seedlings, giving a total of 25 rootstocks per tube. The rootstock of Rangpur lime with a diameter of $7 \mathrm{~mm}$, was the most suitable for the propagation of seedlings of the tangerine cultivar Ponkan (Citrus reticulata Blanco), presenting the best vegetative growth of the graft, with a protrusion time of 91 DAE, surpassing the time for the formation of the citrus seedlings obtained from the other diameters $(4,5$ and $6 \mathrm{~mm})$. The hydroponic system was shown to be a viable technique for propagating citrus seedlings.
\end{abstract}

Key words: Tangerine. Hydroponics. Plants propagation.

\footnotetext{
*Autor para correspondência

${ }^{1}$ Recebido para publicação em 06/04/2012; aprovado em 12/04/2013

Parte da Dissertação de Mestrado apresentada ao Programa de Pós-Graduação em Agronomia da Universidade Federal de Lavras/UFLA

${ }^{2}$ Departamento de Agricultura, Universidade Federal de Lavras/UFLA, Campus Universitário, Lavras-MG. Brasil, 37.200-000, alinedasgracas@ yahoo.com.br ${ }^{3}$ Departamento de Ciência do Solo, Universidade Federal Lavras/UFLA, Campus Universitário, Lavras-MG, Brasil, 37.200-000, vafaquin@ dcsufla.br ${ }^{4}$ Departamento de Fitotecnia da Universidade Federal Lavras (UFLA) Campus Universitário, Lavras-MG. Brasil, 37200-000, nchalfun@ dagufla.br

${ }_{5}^{5}$ Departamento de Ciências Exatas, Universidade Federal de Alagoas/UFAL, Campus Universitário, Arapiraca-AL, Brasil, ademariasouza@yahoo.com.br
} 


\section{INTRODUÇÃO}

A citricultura brasileira produz 18 milhões de toneladas anuais de laranjas, o que representa $28 \%$ do total mundial; são cerca de 800 mil hectares cultivados no País (FOOD AND AGRICULTURE ORGANIZATION, 2010), dos quais, $70 \%$ a $80 \%$ localizam-se no Estado de São Paulo. A manutenção desse parque requer um grande número de mudas para o plantio de pomares, o que é evidenciado pela produção de mais de 22 milhões de mudas por cerca de 550 viveiros comerciais no Estado de São Paulo em 2008 (FUNDO DE DEFESA DA CITRICULTURA, 2010).

A instalação dos pomares cítricos ocorre, utilizando-se mudas enxertadas. Esse método de propagação apresenta diversas vantagens, tais como precocidade e uniformidade de produção, qualidade dos frutos, facilidade na colheita e nos tratos culturais, maior tolerância a pragas e a seca (POMPEU JUNIOR, 2005).

O cultivo de mudas cítricas em ambiente protegido favorece a produção de plantas de elevada qualidade genética e sanitária. Este cultivo necessita ser feito em recipientes, onde as mudas produzidas alteram seu desenvolvimento em função do meio de cultivo, quando comparado com o processo a campo, com a limitação do espaço para o crescimento das raízes (FOCHESATO et al., 2007). Uma boa alternativa pode estar na otimização dos métodos de propagação em hidroponia, os quais têm como objetivos a redução do tempo para obtenção, e o maior controle das condições nutricionais e fitossanitárias.

Bons resultados para várias culturas estão sendo obtidos com o cultivo hidropônico, dentre esses destacamse espécies florestais, ornamentais, frutíferas, fumo e também, com grande viabilidade na produção de batatasemente pré-básica, além da produção de hortaliças de folhas (ANDRIOLO et al., 2009; CALVETE et al., 2007; FURLANI, 1999; MULLER et al., 2007; TRINDADE et al., 2007; SOUZA et al., 2011a; SOUZA et al., 2011b; VILLELA JÚNIOR et al., 2003).

A produção de mudas enxertadas de citrus em hidroponia é inédita, tornando-se necessário avaliar a viabilidade de produção nesse método promissor de propagação. Assim, realizou-se o presente trabalho conduzido em sistema hidropônico com o objetivo de avaliar a viabilidade da produção de porta-enxertos Limoeiro cravo; determinar o diâmetro ótimo dos porta-enxertos de limoeiro 'Cravo' para execução de enxertia da cultivar tangerineira 'Ponkan'e avaliar a viabilidade da produção de mudas enxertadas da cultivar tangerineira 'Ponkan', sobre o crescimento do enxerto até a obtenção da muda no ponto comercial.

\section{MATERIAL E MÉTODOS}

$\mathrm{O}$ experimento foi conduzido em duas etapas no setor de Hidroponia do Departamento de Ciência do Solo da Universidade Federal de Lavras (UFLA), localizada no município de Lavras, MG, nas coordenadas $21^{\circ} 13$ ' $55^{\prime}$ ' S e $44^{\circ} 57^{\prime} 43^{\prime}$ W, a uma altitude de $925 \mathrm{~m}$. O clima do município é do tipo Cwb segundo a classificação de Köppen (mesotérmico com verões brandos e suaves e estiagem de inverno).

Aos 38 dias após a semeadura dos porta-enxertos Limoeiro cravo (Citrus limonia L. Osbeck), foi realizado o desbaste deixando apenas uma plântula por tubetes plásticos, com $5 \mathrm{~cm}$ de diâmetro e $20 \mathrm{~cm}$ de altura, contendo como substrato a vermiculita e colocados em suportes próprios sendo transferidos em seguida para caixas rasas niveladas, denominadas de piscinas, onde passaram a receber uma solução nutritiva proposta por Faquin e Chalfun (2009).

A piscina foi previamente dimensionada, com tamanho suficiente para comportar os tubetes e ligada a um reservatório de 1.000 litros de solução nutritiva. Na piscina os tubetes permanecem com sua parte inferior imersa a uma lâmina de cerca de cinco centímetros de solução nutritiva. Assim, a irrigação e a nutrição das plantas foram realizadas por capilaridade da própria vermiculita. A circulação da solução nutritiva na piscina foi realizada por meio de uma motobomba ligada ao reservatório, que era acionada por um temporizador ("timer"), a intervalos de 15 minutos. $\mathrm{O}$ excesso de solução nutritiva da piscina retornava ao reservatório por gravidade, através de uma tubulação própria. A reposição de nutrientes na solução nutritiva do reservatório foi efetuada por meio da condutividade elétrica, ajustandose diariamente seu valor, pela adição de soluções estoque de macro e micronutrientes, (FAQUIN; CHALFUN, 2009).

Foram realizados quatro experimentos por etapa. A primeira etapa foi desenvolvida no período de outubro de 2008 a fevereiro de 2009, com o intuito de avaliar a viabilidade da produção de porta-enxertos Limoeiro cravo (Citrus limonia L. Osbeck). Os tratamentos dos experimentos $1 ; 2 ; 3$ e 4 corresponderam às épocas de avaliação (semanas) para os porta-enxertos atingirem, respectivamente em cada experimento, os diâmetros médios de caule de 4; 5; 6 e 7 $\mathrm{mm}$, medidos a $10 \mathrm{~cm}$ do colo.

A segunda etapa foi desenvolvida no período de março a maio de 2009, também com quatro experimentos, e constituiu na enxertia dos porta-enxertos com diferentes diâmetros do caule (4; 5; 6 e $7 \mathrm{~mm}$ ) obtidos na primeira etapa. Foram enxertadas borbulhas da cultivar tangerineira 'Ponkan', (Citrus reticulata Blanco), utilizando o método de enxertia de borbulhia em " $\mathrm{T}$ " invertido, realizado à $10 \mathrm{~cm}$ do colo da muda no período da manhã, usando-se fita plástica transparente, 
para permitir uma melhor aderência da borbulha. Após a enxertia utilizou-se o método de decotamento total, a uma altura de $5 \mathrm{~cm}$ do enxerto. Aos 10 dias após a enxertia, foi retirada a fita plástica do enxerto. As mudas cítricas enxertadas permaneceram na piscina conduzidas em haste única, sendo tutoradas para um crescimento vertical e reto, até atingirem $30 \mathrm{~cm}$ de altura (muda comercialmente pronta), medidos semanalmente a partir do colo da planta.

Empregaram-se, em ambas as etapas para todos os experimentos o delineamento experimental inteiramente casualizado. Sendo o tratamento de cada experimento às épocas de avaliação (semanas) composta por cinco repetições de cinco plantas cada (uma em cada tubete), totalizando 25 plantas por experimento.

$\mathrm{Na}$ primeira etapa, avaliou-se para cada experimento o tempo para que 60 a $75 \%$ das plântulas atingissem o ponto de enxertia desejado em cada experimento (diâmetros de $4 ; 5 ; 6$ e $7 \mathrm{~mm}$ para os experimentos $1 ; 2 ; 3$ e 4 , respectivamente). Na segunda etapa, também para cada experimento de diâmetro da primeira etapa, avaliou-se o tempo para obtenção da muda enxertada no ponto comercial (30 cm de altura).

As seguintes características foram avaliadas semanalmente: primeira fase - diâmetro da haste $(\mathrm{mm})$ tomado a $10 \mathrm{~cm}$ do colo e altura $(\mathrm{cm})$ do porta-enxerto e, segunda fase - comprimento do broto do enxerto $(\mathrm{cm})$, medido do ponto de enxertia até o ápice da haste.
Os dados obtidos em cada experimento foram submetidos à análise de variância e regressão polinomial pelo programa estatístico SISVAR (FERREIRA, 2000).

\section{RESULTADOS E DISCUSSÃO}

De acordo com a análise de variância para as características de crescimento avaliadas nos portaenxertos e nos enxertos, houve efeito significativo do tempo sobre a altura e o diâmetro dos porta-enxertos da cultivar limoeiro 'Cravo' (Tabela 1) e sobre a altura dos enxertos de tangerina "Ponkan" (Tabela 2).

As Figuras 1 e 2 registram o crescimento dos porta-enxertos de limoeiro 'Cravo' com relação à altura e diâmetro do caule obtido a $10 \mathrm{~cm}$ do colo; houve uma resposta linear significativa $(\mathrm{p}<0,05)$ em relação aos dias de amostragem sobre a altura e uma resposta quadrática significativa $(\mathrm{p}<0,05)$ sobre o diâmetro do caule nos quatro experimentos avaliados.

Um fator importante no desenvolvimento do portaenxertoé o diâmetro da haste, pois o maior desenvolvimento em diâmetro pode antecipar o tempo de enxertia. Neste trabalho, verificou-se que o diâmetro para atingir o ponto de enxertia, foi alcançado aos 84 dias (4 mm); aos 98 dias (5 mm); aos 125 dias (6 mm) e aos 140 dias (7 mm), a uma altura de $10 \mathrm{~cm}$ do colo da planta (Figura $2 \mathrm{a}, \mathrm{b}, \mathrm{c}, \mathrm{d}$ ).

Tabela 1 - Resumo da analise de variância do efeito do tempo na altura e no diâmetro dos porta-enxertos da cultivar limoeiro 'Cravo'

\begin{tabular}{|c|c|c|c|c|c|}
\hline & & \multicolumn{2}{|c|}{ Altura $(\mathrm{cm})$} & \multicolumn{2}{|c|}{ Diâmetro (mm) } \\
\hline \multirow{4}{*}{$4 \mathrm{~mm}$} & $\mathrm{FV}$ & GL & QM & GL & QM \\
\hline & Tempo & 11 & $878,856152 * *$ & 11 & $7,959556 * *$ \\
\hline & Erro & 48 & 5,479607 & 48 & 0,105403 \\
\hline & $\mathrm{CV}(\%)$ & 8,61 & 11,87 & & \\
\hline \multirow{4}{*}{$5 \mathrm{~mm}$} & $\mathrm{FV}$ & GL & QM & GL & QM \\
\hline & Tempo & 13 & $1011,656276^{* *}$ & 13 & $10,291870 * *$ \\
\hline & Erro & 56 & 3,599149 & 56 & 0,085720 \\
\hline & $\mathrm{CV}(\%)$ & 6,33 & 9,90 & & \\
\hline \multirow{4}{*}{$6 \mathrm{~mm}$} & $\mathrm{FV}$ & GL & QM & GL & QM \\
\hline & Tempo & 17 & $897,707059 * *$ & 17 & $13,379468 * *$ \\
\hline & Erro & 72 & 9,280889 & 72 & 0,067691 \\
\hline & $\mathrm{CV}(\%)$ & 8,42 & 7,75 & & \\
\hline \multirow{4}{*}{$7 \mathrm{~mm}$} & $\mathrm{FV}$ & GL & QM & GL & QM \\
\hline & Tempo & 19 & $1478,903768 * *$ & 19 & $15,959845 * *$ \\
\hline & Erro & 80 & 4,029300 & 80 & 0,153450 \\
\hline & $\mathrm{CV}(\%)$ & 5,00 & 10,56 & & \\
\hline
\end{tabular}

F.V. Fontes de variação; G.L. Grau de liberdade; Q.M. Quadrado médio; ** Significativo, pelo teste de F, a 0,01\% 
Tabela 2 - Resumo da analise de variância do efeito do tempo na altura dos enxertos de tangerina "Ponkan"

\begin{tabular}{|c|c|c|c|}
\hline & & Altura (c & \\
\hline \multirow{4}{*}{$4 \mathrm{~mm}$} & $\mathrm{FV}$ & GL & QM \\
\hline & Tempo & 19 & $370,603684 * *$ \\
\hline & Erro & 80 & 2,693216 \\
\hline & $\mathrm{CV}(\%)$ & 13,20 & \\
\hline \multirow{4}{*}{$5 \mathrm{~mm}$} & $\mathrm{FV}$ & GL & $\mathrm{QM}$ \\
\hline & Tempo & 17 & $324,011221 * *$ \\
\hline & Erro & 72 & 15,740021 \\
\hline & $\mathrm{CV}(\%)$ & 34,09 & \\
\hline \multirow{4}{*}{$6 \mathrm{~mm}$} & $\mathrm{FV}$ & GL & $\mathrm{QM}$ \\
\hline & Tempo & 14 & $302,356585 * *$ \\
\hline & Erro & 60 & 7,278942 \\
\hline & $\mathrm{CV}(\%)$ & 22,16 & \\
\hline \multirow{4}{*}{$7 \mathrm{~mm}$} & $\mathrm{FV}$ & $\overline{G L}$ & QM \\
\hline & Tempo & 13 & $302,815297 * *$ \\
\hline & Erro & 56 & 16,337429 \\
\hline & $\mathrm{CV}(\%)$ & 32,72 & \\
\hline
\end{tabular}

F.V. Fontes de variação; G.L. Grau de liberdade; Q.M. Quadrado médio; ** Significativo, pelo teste de F, a 0,01\%

Figura 1 - Evolução da altura dos porta-enxertos da cultivar limoeiro 'Cravo', até atingir os pontos de enxertia de 4 (a); 5 (b); 6 (c) e $7 \mathrm{~mm}$ (d)
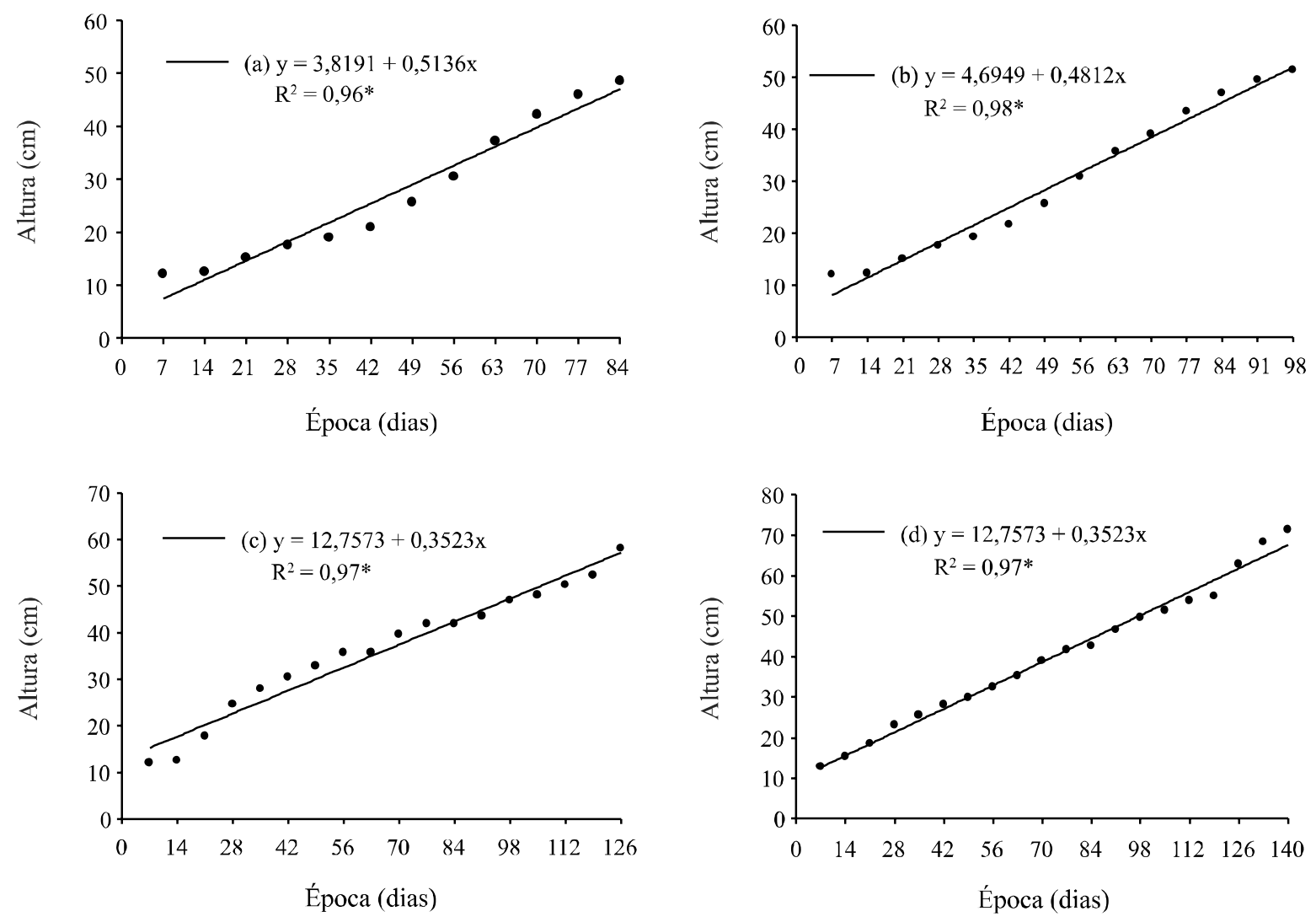
Figura 2- Evolução do diâmetro dos porta-enxertos da cultivar limoeiro 'Cravo', até atingir os pontos de enxertia de 4 (a); 5 (b); 6 (c) e $7 \mathrm{~mm}(\mathrm{~d})$
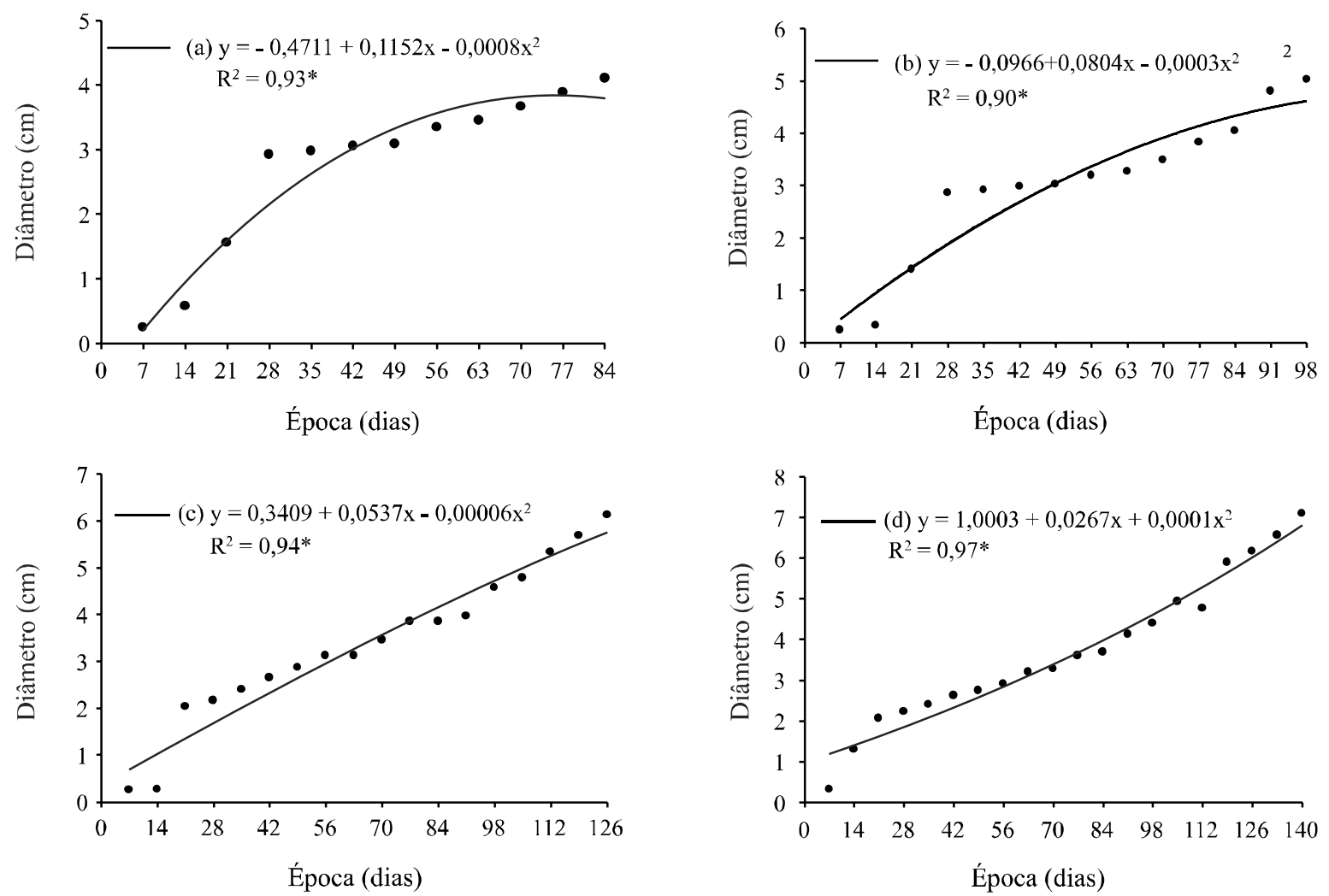

Vasconcelos et al. (1985) estudando o efeito da altura de enxertia e método de forçamento na formação de mudas cítricas, concluíram que o método de forçamento com decotamento total, a uma altura de $5 \mathrm{~cm}$ promoveu maior crescimento da haste do enxerto. Apenas ressaltando que no presente estudo o método utilizado na formação da muda de tangerineira 'Ponkan' foi o forçamento total, a altura de $5 \mathrm{~cm}$ promovendo um pegamento e crescimento satisfatório do enxerto.

Esposti e Siqueira (2004), estudando a influência de doses de nitrogênio, aplicadas em cobertura na forma de ureia, no crescimento de diferentes porta-enxertos de citros, cultivados em recipientes conduzido em casa de vegetação no sistema tradicional, observaram que o limoeiro 'Cravo' atingiu o diâmetro para o ponto de enxertia de 4; $5 ; 6$ e $7 \mathrm{~mm}$, a uma altura de $5 \mathrm{~cm}$ do colo, aos 180; 215; 260 e 305 dias após a semeadura, respectivamente. Em comparação ao presente trabalho, o diâmetro obtido a $10 \mathrm{~cm}$ do colo dias após semeadura sob condições hidropônicas, houve uma antecipação do ponto de enxertia do porta-enxerto de $96 ; 117 ; 135$ e 165 dias para o diâmetro de 4; 5; 6 e

$7 \mathrm{~mm}$, respectivamente, chegando dessa forma mais precocemente ao ponto de enxertia (Figura $2 \mathrm{a}, \mathrm{b}, \mathrm{c}, \mathrm{d}$ ). Provavelmente a antecipação de resultados possa ser explicada em função de as condições de propagação em sistema tradicional ser bastante diferentes das utilizadas nessa pesquisa (sistema hidropônico). Ressalta-se que o sistema hidropônico permite um perfeito controle da nutrição e sanidade vegetal, fatores esses determinantes para o bom crescimento das plantas (SOUZA et al., 2011a).

Resultados encontrados por Fortes (1991) e Rezende (1991) revelam que o limoeiro 'Cravo' necessita de 195 a 265 dias após a semeadura para alcançar um diâmetro do caule de $5 \mathrm{~mm}$ a $15 \mathrm{~cm}$ de altura do colo; logo, no presente experimento, o limoeiro 'Cravo' apresentou um tempo de 98 dias com o diâmetro do caule de $5 \mathrm{~mm}$ a $10 \mathrm{~cm}$ de altura do colo (Figura 2 b).

Na figura 3, estão apresentadas as avaliações da altura dos brotos dos enxertos das mudas enxertadas em porta enxertos de diferentes diâmetros obtidos na segunda fase. Houve efeito significativo do tempo sobre 
a altura $(\mathrm{p}<0,05)$, a brotação mais precoce iniciou aos 14 dias após a enxertia (DAE) com a enxertia realizada no diâmetro do caule de $7 \mathrm{~mm}$.

Observa-se que com o aumento do diâmetro do caule dos porta-enxertos (4; 5; 6 e $7 \mathrm{~mm}$ ) utilizados para enxertia da tangerina "Ponkan", ocorreu uma diminuição do tempo para a formação da muda cítrica no ponto comercial, que é de $30 \mathrm{~cm}$. Sendo que os porta-enxertos Limoeiro 'Cravo' com maior diâmetro (7 mm), apresentaram o melhor crescimento vegetativo do enxerto, sobressaindo com tempo 91 DAE, superando o tempo para a formação das mudas cítricas obtidas com os demais diâmetros (4; 5 e 6 mm).

Embora o tempo para obtenção dos portaenxertos com diâmetro do caule de $7 \mathrm{~mm}$ seja superior ao tempo de obtenção dos porta-enxertos com os demais diâmetros (Figura 2), houve uma compensação desse período quando compara-se o tempo para obtenção de mudas aptas a serem plantadas no campo. Existe um grande interesse na diminuição do tempo para a formação da muda cítrica e no controle das condições fitossanitárias, uma vez que isto gera benefícios, tanto na própria comercialização da muda quanto no futuro pomar a ser instalado.
Segundo a portaria ADAESP - 1, de 10/02/2003, o enxerto deve ser feito entre 10 e $20 \mathrm{~cm}$ de altura, contados a partir do colo da planta e a haste principal deve estar a uma altura de, no mínimo, $30 \mathrm{~cm}$ (trinta centímetros) de altura para as tangerinas, contada a partir do colo da planta. Desse modo, no presente estudo a altura do broto do enxerto de $20 \mathrm{~cm}$ foi alcançada aos 126 e 119 DAE, Figura 3 (a e b) que, somados com os $10 \mathrm{~cm}$ do porta-enxerto Limoeiro 'Cravo', alcança o tamanho mínimo de $30 \mathrm{~cm}$ da muda comercialmente pronta atendendo às normas estabelecidas pela portaria ADAESP-1 (CARVALHO, 2003).

Bernardi et al. (2000), em estudo com o mesmo porta-enxerto de limoeiro "Cravo" sob condições de telado, observaram que o tempo para atingir o ponto de plantio no campo foi de 180 DAE. Em comparação com esse trabalho, o enxerto sob condições hidropônicas antecipou em 89 dias o ponto de plantio no campo. Salienta-se, ainda, que Bernardi et al., (2000) obtiveram as mudas de laranjeira 'Valência' (Citrus sinnensis L. Osbeck) aptas ao plantio em prazo de, aproximadamente, 420 dias após a semeadura. Nas condições hidropônicas do presente trabalho, obtiveram-se o ponto de plantio no campo aos 231 dias após semeadura, totalizando a antecipação de 189 dias (Figura 3) na obtenção de mudas de tangerineira 'Ponkan' aptas a serem plantadas em campo.

Figura 3 - Altura média das brotações dos enxertos de tangerina 'Ponkan', (Citrus reticulata Blanco), sobre os porta-enxertos com 4; 5; 6 e 7 mm de diâmetro do caule

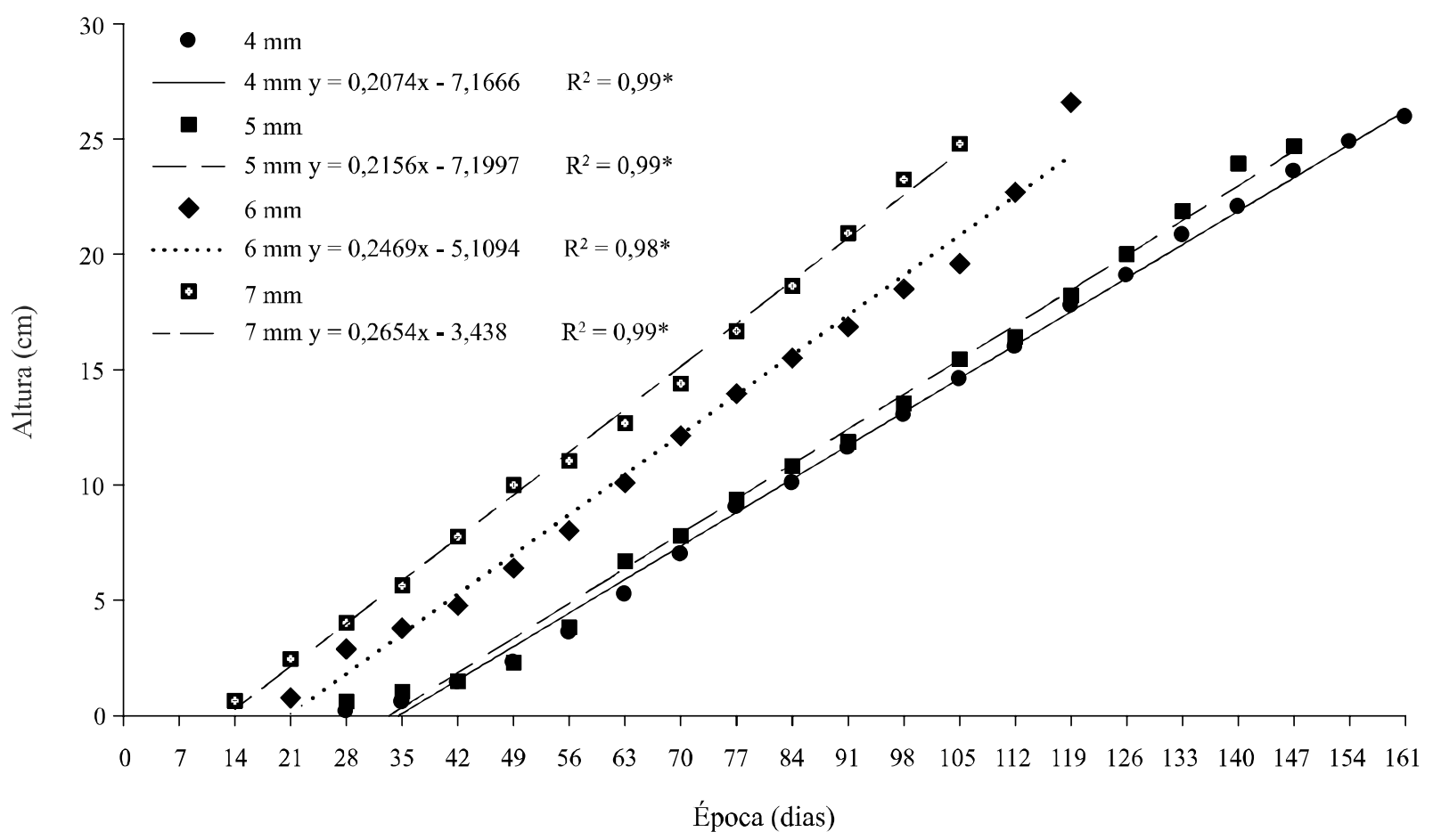


Rezende et al. (2010), em estudo com o mesmo porta-enxerto de limoeiro "Cravo" e a variedade copa laranja 'Pêra' (Citrus sinensis L. Osbeck) cultivados em vasos através do sistema de fertirrigação em casa de vegetação, obtiveram o ponto de plantio no campo aos 360 dias. Assim, no presente estudo em condições hidropônicas, o tempo para o plantio foi de 231 dias, havendo, portanto uma antecipação de 129 dias.

Possivelmente, essa abreviação na formação da muda está aliado ao ambiente mais favorável obtido dentro da casa de vegetação, devido à disponibilidade de água. Também os nutrientes estão prontamente disponíveis, permitindo que as plantas tenham crescimento mais rápido, encurtando o ciclo produtivo, aumentando a produtividade e a ocorrência de doenças é minimizada, de modo que há expressivo ganho quando se compara o cultivo tradicional com o cultivo hidropônico, ainda que os ganhos variem de uma cultura para outra (SOUZA et al., 2011a; SOUZA et al., 2011b).

\section{CONCLUSÕES}

1.O sistema hidropônico mostrou-se uma técnica viável na produção de mudas enxertadas de tangerineira 'Ponkan';

$2 . \mathrm{O}$ diâmetro $7 \mathrm{~mm}$ é o mais apropriado à produção de mudas de tangerineira 'Ponkan' no sistema hidropônico, estando as mesmas prontas para comercialização aos 231 dias após a semeadura.

\section{REFERÊNCIAS}

ANDRIOLO, J. L. et al. Cultivo sem solo do morangueiro com três métodos de fertirrigação. Ciência Rural, v. 39, n. 3, p. 691-695, 2009.

ANUÁRIO Brasileiro de Fruticultura. Santa Cruz do Sul: Editora Gazeta, 2010. 129 p.

BERNARDI, A. C. C. et al. Desenvolvimento de mudas de citros cultivadas em vaso em resposta à adubação NPK. Scientia Agricola, v. 57, n. 4, p. 733-738, 2000.

CALVETE, E. O. et al. T. Produção hidropônica de morangueiro em sistema de colunas verticais, sob cultivo protegido. Revista Brasileira de Fruticultura, v. 29, n. 3, p. 524-529, 2007.

CARVALHO, S. A. Regulamentação atual da agência de defesa agropecuária para produção, estocagem, comércio, transporte e plantio de mudas cítricas no estado de São Paulo. Laranja, v. 24, n. 1, p. 199-239, 2003.

ESPOSTI, M. D. D.; SIQUEIRA, D. L. Doses de uréia no crescimento de porta-enxertos de citros produzidos em recipientes. Revista Brasileira de Fruticultura, v. 26, n. 1, p. 136-139, 2004.

FOOD AND AGRICULTURE ORGANIZATION OF THE UNITED NATIONS. Agriculture production: citrus production. Disponível em: <http://faostat.fao.org>. Acesso em: 10 maio 2010.

FAQUIN, V.; CHALFUN, N. N. J. Hidromudas: Processo de produção de porta-enxerto de mudas frutíferas, florestais e ornamentais enxertadas em hidroponia. 2008. Disponível em:〈http://www.inpi.gov.br/menu-superior/pesquisas> Acesso em: 18 dez. 2009.

FERREIRA, D. F. Analise estatística por meio do SISVAR para Windows 4.0. In: Reunião anual da região brasileira da sociedade internacional da biometria, 45., 2000, São Carlos. São Carlos, SP: UFSCAR, 2000. p. 255-258.

FOCHESATO, M. L. et al. Crescimento vegetativo de portaenxertos de citros produzidos em substratos comerciais. Ciência Rural, v. 37, n. 4, p. 970-975, 2007.

FORTES, L. A. Processos de produção do porta-enxerto limoeiro (Citrus limonia Osbeck cv 'Cravo') em vaso. 1991. 96 f. Dissertação (Mestrado em Fitotecnia) - Universidade Federal de Lavras, Lavras, 1991.

FUNDO DE DEFESA DA CITRICULTURA. Viveiros e mudas. Disponível em: <http://www.fundecitrus.com.br/ dviveiros_br.html>. Acesso em: 14 out. 2010.

FURLANI, P. R.; Hydroponic vegetable production in Brazil. Acta Horticulturae, v. 481, n. 6, p. 777-778, 1999.

MULLER, D. R. et al. Produção hidropônica de batata em diferentes concentrações de solução nutritiva e épocas de cultivo. Pesquisa Agropecuária Brasileira, v. 42, n. 5, p. 647-653, 2007.

POMPEU JUNIOR, J. Porta-enxertos. In: MATTOS JUNIOR, D. et al (Ed.). Citros. Campinas: Instituto Agronômico/ Fundag, 2005. p. 63-94.

REZENDE, C. F. A. et al. Crescimento e acúmulo de nutrientes em mudas cítricas cultivadas em ambiente protegido Bioscience Journal, v. 26, n. 3, p. 367-375, 2010 .

REZENDE, L. P. Efeito do volume de substrato e do superfosfato simples na formação de porta-enxertos de citros. 1991. 97 f. Dissertação (Mestrado em Fitotecnia) - Universidade Federal de Lavras, Lavras, 1991.

SOUZA, A. G. et al. Production of peach grafts under hydroponic conditions. Scientia Agraria, v. 12, n. 6, p. 266268, 2011a.

SOUZA, A. G. et al. Production of pear grafts under hydroponic conditions. Ciência e Agrotecnologia, v. 35, n. 2, p. 322-326, $2011 b$.

TRINDADE, C. S. F. et al. Efeito dos Sistemas Orgânico, Hidropônico e Convencional na Qualidade da Alface Lisa. Brazilian Journal of Food Technology, v. 10, n. 2, p. 111115, 2007. 
VASCONCELOS, L. A. B. C. et al. Efeitos da altura de enxertia e método de forçamento na formação de mudas cítricas. Pesquisa Agropecuária Brasileira, v. 20, n. 5, p. 595-597, 1985.
VILLELA JUNIOR, L. V. E. et al. Comportamento do meloeiro em cultivo sem solo com a utilização de biofertilizante. Horticultura Brasileira, v. 21, n. 2, p. 153-157, 2003. 